Article

\title{
Effects of Powder Feed Rate on Formation of Fully Equiaxed $\beta$ Grains in Titanium Alloys Fabricated by Directed Energy Deposition
}

\author{
Qiang Zhang ${ }^{1, * \mathbb{C}}$, Siyu Zhang ${ }^{2}$, Min Zheng ${ }^{2}$, Yongchao Ou ${ }^{1}$, Shang Sui ${ }^{3}$, Jing Chen ${ }^{2, *}$, \\ Xiaojian Wang ${ }^{1}\left(\mathbb{D}\right.$ and Wei Li ${ }^{1}$ \\ 1 Institute of Advanced Wear \& Corrosion Resistance and Functional Materials, Jinan University, \\ Guangzhou 510632, China \\ 2 State Key Laboratory of Solidification Processing, Northwestern Polytechnical University, \\ Xi'an 710072, China \\ 3 Singapore Institute of Manufacturing Technology, 73 Nanyang Drive, Singapore 637662, Singapore \\ * Correspondence: zhangqiang2017@jnu.edu.cn (Q.Z.); phd2003cjj@nwpu.edu.cn (J.C.); \\ Tel.: +86-20-85220890 (Q.Z.); +86-29-88494001 (J.C.)
}

Received: 25 March 2020; Accepted: 15 April 2020; Published: 17 April 2020

\begin{abstract}
A near $\beta$ titanium alloy, Ti5Al2Sn2Zr4Mo4Cr, was fabricated by directed energy deposition (DED) with different powder feed rates to investigate the formation of fully equiaxed $\beta$ grains. A two-dimensional numerical model was developed to investigate the thermal conditions of the molten pool. Experimental results showed that the formation of an epitaxial cellular structure at the bottom of the molten pool is almost unavoidable. An increase in the powder feed rate produces a moderate thermal condition and promotes the formation of equiaxed grains in a single cladding layer. However, it could not guarantee the formation of a fully equiaxed microstructure in a block sample. From a low to high powder feed rate, fully columnar, mixed equiaxed-columnar, and fully equiaxed microstructures were obtained. Grain morphology was also affected by the remolten process. Increasing the powder feed rate reduced the remolten depth and broke the continuity of the epitaxial cellular structure, leading to different grain morphologies.
\end{abstract}

Keywords: additive manufacturing; directed energy deposition; titanium alloy; equiaxed $\beta$ grains; grain morphology evolution; overlap zone

\section{Introduction}

Additive manufacturing (AM) is a type of near net shaping technique to produce three-dimensional parts [1]. Directed energy deposition (DED) is a powder feed additive manufacturing technique that has been widely researched in the past decades. DED has been considered as an appropriate and cost-effective technology to produce high-performance complex titanium alloy products in a near net shape $[2,3]$.

With the purpose of wide applications of DED titanium products, a competitive mechanical property should be achieved. The mechanical properties of the end products of titanium alloys are strongly affected by the microstructure characteristics [4]. The prevailing $\beta$ grain morphology of DED titanium alloys was presented as epitaxial columnar grains. It has been verified in Ti6Al4V [5,6], Ti6.5Al2V1.5Mo0.5Zr0.3Si [7], and Ti6Al2Zr2Sn3Mo1.5Cr2Nb [8] alloys fabricated by DED in a very wide processing window. Furthermore, the coarse columnar $\beta$ grains usually exhibit a strong $<100>$ fiber texture [8]. The columnar grains with strong texture and the resulting continuous $\alpha$ layers along the grain boundaries generally lead to anisotropic mechanical properties [9,10]. Producing fine equiaxed $\beta$ grains in the DED titanium parts is a practicable solution to overcome the limitations [11]. 
The classical solidification theory indicates that with decreasing G/R ratios (G: temperature gradient, R: growth rate of solid/liquid interface), the planar, cellular, columnar dendritic, and equiaxed dendritic structures are expected during the solidification processes of alloys [12]. However, due to the intrinsic characteristics of the molten pool and the titanium alloys, equiaxed $\beta$ grains are rare in DED titanium alloys. For most of the titanium alloys, almost no equiaxed $\beta$ grains were reported in previous references. Post heat treatment is not an effective method to change the grain morphology from columnar to equiaxed, either. Experimental results showed that heat treatment below the $\beta$ transus has a negligible effect on $\beta$ grain morphology evolution, whereas heat treatment above the $\beta$ transus will lead to extensive grain growth, which usually deteriorates the mechanical properties [13]. As a consequence, promoting the columnar to equiaxed transition (CET) in titanium alloys during AM has become a significant challenge. The composition design of titanium alloys is a possible way to control the grain morphology; in Xue et al.'s [14] study, they found that the prior $\beta$ grains could be refined after the addition of boron. Recent research studies showed that increasing the powder feed rate could strongly increase the tendency of CET in Ti6.5Al3.5Mo1.5Zr0.3Si [15] and Ti6Al2Sn2Zr3Mo1.5Cr2Nb alloys [16] without changing the original compositions of the alloys. It has been noted that the cases in which CET was achieved during the DED process mainly occur in the titanium alloys containing more alloying elements. Further studies suggested that suitable alloying solutes that could develop constitutional supercooling combined with a population of potent heterogeneous nucleant seems essential for CET during AM $[17,18]$. In the above-mentioned cases, the alloying elements, such as B, $\mathrm{Mo}$, and $\mathrm{Cr}$, could generate constitutional supercooling, and the increased the powder feed rate resulted in the presence of partially melted powders that could act as heterogeneous nucleants. However, the equiaxed $\beta$ grains could not be guaranteed in a block sample, although a single layer containing equiaxed $\beta$ grains was deposited [19]. It was found that in a single-track multi-layer sample, a smaller remelting depth was critical for the reserve of equiaxed grains. Compared with increasing the nominal $\mathrm{Z}$-axis increment, lowering the temperature of the previous layers is a more effective way to reduce the remelting depth $[16,18]$. There is still a challenge in achieving fully equiaxed $\beta$ grains in a multi-track multi-layer sample during AM.

The aim of the present study is to further understand the formation of equiaxed $\beta$ grains and the $\beta$ grain morphology evolution during a multi-layer deposition process. In this study, a near $\beta$ titanium alloy, Ti5Al2Sn2Zr4Mo4Cr, which can achieve equiaxed $\beta$ grains during $\mathrm{AM}$, was used as the deposited material. A two-dimensional numerical model was developed to investigate the thermal conditions of the molten pool. A simplified model was used to estimate the temperature drop caused by the captured cold powder particles. The effects of the powder feed rate on the microstructure and local texture characteristics were investigated. Based on the experimental and simulated results, the $\beta$ grain morphology evolution during DED was discussed.

\section{Experimental Procedures and Mathematical Models}

\subsection{Experimental Procedures}

All the samples were fabricated by DED equipment consisting of a continuous wave semiconductor laser with a maximum power of $6 \mathrm{~kW}$, a 5-axis numerical control table, a coaxial powder feeder, and an argon gas chamber. A wrought Ti5Al2Sn2Zr4Mo4Cr plate with dimensions of $120 \mathrm{~mm} \times 75 \mathrm{~mm} \times 10 \mathrm{~mm}$ was used as the substrate, and the surface was ground with $\mathrm{SiC}$ papers and then cleaned with acetone and ethanol. Ti5Al2Sn2Zr4Mo4Cr spherical powders with the diameter ranges from 80 to $120 \mu \mathrm{m}$ were used. The powders were dried in a vacuum oven for $2 \mathrm{~h}$ at $120 \pm 5^{\circ} \mathrm{C}$ to eliminate moisture absorption and ensure that the powders have good flowability.

To control the oxygen content, the argon was inlet into the gas chamber through the inlets at the bottom, and it purged air through the outlets at the top. The single-cladding layers were deposited after the argon was inlet into the chamber for several minutes. Five three-track 10-layer samples were deposited until the surface of the single cladding layer has a silvery luster. The lengths of the 
deposited samples are about $100 \mathrm{~mm}$ for the first nine layers, but $90 \mathrm{~mm}$ for the last layer. In this study, the samples were deposited with the powder feed rate increasing while the all other processing parameters were kept constant. The nomenclature and the corresponding processing parameters of the DED samples were listed in Table 1 . The unit of the powder feed rate $(\mathrm{r} / \mathrm{min})$ was used due to the powder feeder regulation system. The zigzag scanning strategy with a rotation of $180^{\circ}$ between successive layers was adopted. The deposited samples and the schematic of the scanning strategy are shown in Figure 1.

Table 1. The nomenclature and the corresponding processing parameters of the directed energy deposition (DED) samples.

\begin{tabular}{ccccc}
\hline Sample & $\begin{array}{c}\text { Laser Power } \\
(\mathbf{W})\end{array}$ & $\begin{array}{c}\text { Scanning Velocity } \\
(\mathbf{m m} / \mathbf{s})\end{array}$ & $\begin{array}{c}\text { Powder Feed Rate } \\
(\mathbf{r} / \mathbf{m i n})\end{array}$ & $\begin{array}{c}\text { Spot Diameter } \\
(\mathbf{m m})\end{array}$ \\
\hline A1 & & & 10 & \\
A2 & & & 20 & 5 \\
A3 & 2200 & 10 & 30 & \\
A4 & & & 40 & \\
A5 & & & 50 & \\
\hline
\end{tabular}

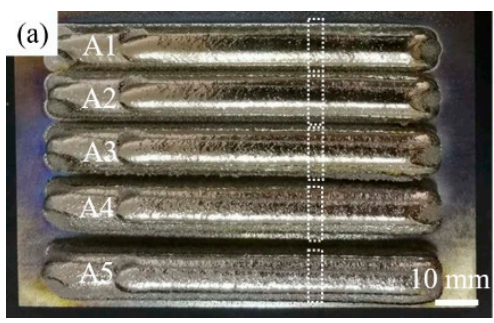

(b)

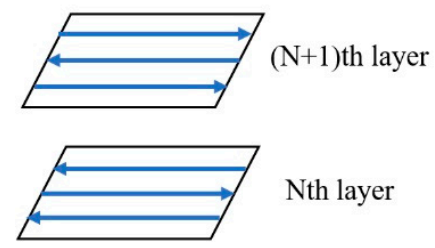

Figure 1. (a) Appearance of the as-deposited samples; (b) schematic of the scanning strategy.

Samples for the microstructure and texture observation were sectioned along the dotted line shown in Figure 1a. The samples were revealed using the Kroll etchant $\left(1 \mathrm{~mL} \mathrm{HF,} 3 \mathrm{~mL} \mathrm{HNO}_{3}\right.$, and $25 \mathrm{~mL} \mathrm{H}_{2} \mathrm{O}$ ) after mounting, grinding, and polishing. The samples were observed using an optical microscope (Keyence, VH-Z50L, Osaka, Japan). The deposition height and the cladding layer height were measured in the optical microscope pictures. The deposition height was measured in the 10th layer and the unmelted part of the ninth layer. The cladding layer height was obtained by measuring the distance between the two adjacent fusion lines.

Before electron back scatter diffraction (EBSD) analysis, the sample was mechanically polished and then electrolytically polished (in 8\% perchloric acid-92\% ethanol, applying $28 \mathrm{~V}, 40 \mathrm{~s}, 20^{\circ} \mathrm{C}$ ). The EBSD patterns were acquired using an EBSD detector (Oxford Instruments plc, NordlysNano, Abingdon, UK), the scan step size is $4.3 \mu \mathrm{m}$ on a rectangular scan grid. EBSD data were processed using HKL Technologies Channel 5 software (Oxford Instruments plc, Abingdon, UK) for orientation analysis and pole figure reconstruction.

\subsection{Mathematical Models}

A two-dimensional numerical model was developed to investigate the thermal and fluid conditions of the molten pool during the DED process. The model is based on the conservation of mass equation, momentum equation, energy equation, and VOF (volume of fluid) equation. The surface tension, Marangoni convection, and buoyancy-driven flow were incorporated into the model. The fluid flow is assumed to be incompressible Newtonian laminar flow. A moving Gaussian distributed laser heat source is applied to the surface of the molten pool. The movement of the powder particles was ignored. The process was simplified to mass addition beneath the liquid/gas interface. The material properties of the Ti5Al2Sn2Zr4Mo4Cr alloy are listed in Table 2. 
Table 2. Thermophysical properties of titanium alloy.

\begin{tabular}{cc}
\hline Property & Value \\
Density & $4400 \mathrm{~kg} \cdot \mathrm{m}^{-3}$ \\
Liquid temperature & $1928 \mathrm{~K}$ \\
Solidus temperature & $1878 \mathrm{~K}$ \\
Specific heat of solid metal & $573 \mathrm{~J} \cdot \mathrm{kg}^{-1} \cdot \mathrm{K}^{-1}$ \\
Specific heat of liquid metal & $750 \mathrm{~J} \cdot \mathrm{kg}-1 \cdot \mathrm{K}^{-1}$ \\
Thermal coefficient of surface tension & $-2.6 \times 10^{-4} \mathrm{~kg} \cdot \mathrm{s}^{-2} \cdot \mathrm{K}^{-1}$ \\
Latent heat of fusion & $2.86 \times 10^{6} \mathrm{~J} \cdot \mathrm{kg}-1$ \\
Viscosity & $5 \times 10^{-3} \mathrm{~Pa} \cdot \mathrm{s}$ \\
Surface tension & $1.5 \mathrm{~N} \cdot \mathrm{m}^{-1}$ \\
Thermal expansion coefficient & $1.3 \times 10^{-5} \mathrm{~K}^{-1}$ \\
Thermal conductivity of liquid metal & $33 \mathrm{~W} \cdot \mathrm{m}^{-1} \cdot \mathrm{K}^{-1}$ \\
Thermal conductivity of solid metal & $13 \mathrm{~W} \cdot \mathrm{m}^{-1} \cdot \mathrm{K}^{-1}$ \\
\hline
\end{tabular}

The VOF method was used to trace the evolution of the liquid/gas interface, and two-phases, argon and titanium alloy, were considered. The VOF equation is

$$
\frac{\partial \alpha_{1}}{\partial t}+\nabla \cdot\left(\alpha_{1} V\right)=0
$$

The summation of the molten metal volume fraction $\alpha_{1}$ and argon volume fraction $\alpha_{2}$ is 1 . $\alpha_{1}=1$ indicates that a cell is full of titanium alloy, and $\alpha_{1}=0$ indicates that a cell is full of argon. The properties $\chi$ appearing in the equations are determined by the presence of the component phases in each control volume.

$$
\chi=\chi_{1} \alpha_{1}+\chi_{2} \alpha_{2}
$$

where $\chi_{1}$ and $\chi_{2}$ represent the properties of titanium alloy and argon, respectively.

The mass conservation equation is

$$
\frac{\partial \rho}{\partial t}+\nabla \cdot(\rho V)=M
$$

The Gaussian distributed mass $M$ is represented as

$$
M=\eta_{p} \frac{M_{p}}{\pi r_{p}^{2}} \exp \left[-\frac{\left(x-v_{p} t\right)^{2}}{r_{p}^{2}}\right]
$$

where $\eta_{p}$ is the absorption factor, $M_{p}$ is the powder feed rate, $r_{p}$ is the laser beam radius, and $v_{p}$ is the moving velocity of the nozzle.

The momentum conservation equation is

$$
\begin{aligned}
& \frac{\partial}{\partial t}(\rho V)+\nabla \cdot(\rho V V)=-\nabla p+\nabla \cdot\left[\mu\left(\nabla V+\nabla V^{T}\right)\right]+\rho \beta\left(T-T_{l}\right) g-A_{m u s h}\left(\frac{\left(1-f_{l}\right)^{2}}{f_{l}^{3}+\varepsilon_{0}}\right) V \\
& +\left[\sigma \kappa \hat{n}+\frac{d \sigma}{d T}(\nabla T-\hat{n}(\hat{n} \cdot \nabla T))\right]|\nabla \alpha| \frac{2 \rho}{\rho_{1}+\rho_{2}}
\end{aligned}
$$

The term $\rho \beta\left(T-T_{l}\right) g$ is buoyancy force, $\beta$ is the thermal expansion coefficient, and $T_{l}$ is the liquids temperature. The Darcy's term, $-A_{m u s h}\left(\frac{\left(1-f_{l}\right)^{2}}{f_{l}^{3}+\varepsilon_{0}}\right) V$ is used to extinguish the velocities in the mushy zone and solidified zone, where $A_{m u s h}$ is the mushy zone constant, $f_{l}$ is the liquid volume fraction, and $\varepsilon_{0}$ is a small number to avoid division by zero. The term $\left[\sigma \kappa \hat{n}+\frac{d \sigma}{d T}(\nabla T-\hat{n}(\hat{n} \cdot \nabla T))\right]|\nabla \alpha| \frac{2 \rho}{\rho_{1}+\rho_{2}}$ is the additional momentum source term that is applied at the liquid/gas interface, including (i) the surface tension, $\sigma \kappa \hat{n}$, where $\sigma$ is the surface tension, $\kappa$ is the surface curvature, $\hat{n}$ is the surface normal, 
and (ii) the Marangoni force, $\frac{d \sigma}{d T}(\nabla T-\hat{n}(\hat{n} \cdot \nabla T))$, which takes into account the effect of temperature gradient on the liquid/gas interface.

The energy conservation equation is

$$
\begin{aligned}
& \frac{\partial}{\partial t}(\rho H)+\nabla \cdot(\rho V H)=\nabla \cdot(\kappa \nabla T) \\
& +\left[\left(-h_{c}\left(T-T_{r e f}\right)-\sigma_{s} \varepsilon\left(T^{4}-T^{4}{ }_{r e f}\right)+Q_{l}\right)\left|\nabla \alpha_{1}\right|\right] \frac{2 \rho}{\rho_{1}+\rho_{2}}
\end{aligned}
$$

$h_{c}\left(T-T_{r e f}\right)$ is convection heat loss, and $\sigma_{s} \varepsilon\left(T^{4}-T_{r e f}{ }^{4}\right)$ is radiation heat loss. The Gaussian distributed laser beam intensity $Q_{l}$ is represented as

$$
Q_{l}=\eta_{l} \frac{2 P_{l}}{\pi r_{l}^{2}} \exp \left[-2 \frac{\left(x-v_{l} t\right)^{2}}{r_{l}^{2}}\right]
$$

where $\eta_{l}$ is the effective absorption factor, $P_{l}$ is the laser power, $r_{l}$ is the laser beam radius, and $v_{l}$ is the laser moving velocity.

The enthalpy $H$ is computed as the sum of the sensible enthalpy, $h$, and the latent heat $\Delta H$, where $h=h_{r e f}+\int_{T_{r e f}}^{T} c_{p} d T, h_{r e f}$ is the reference enthalpy, and $c_{p}$ is the specific heat at constant pressure. $\Delta H=f_{l} L$, in which $L$ is the latent heat of the metal, and the liquid volume fraction $f_{l}$ is expressed as

$$
f_{l}=\left\{\begin{array}{cc}
0 & \left(T \leq T_{s}\right) \\
\frac{T-T_{s}}{T_{l}-T_{s}} & \left(T_{s} \leq T \leq T_{l}\right) \\
1 & \left(T_{l} \leq T\right)
\end{array}\right.
$$

The governing equations were solved using the commercial Computational Fluid Dynamics (CFD) software Fluent (Ansys Inc., PA, USA). The visual analysis software VisIt (Lawrence Livermore National Laboratory, CA, USA) [20] was adopted to extract the simulation results and carry out the further analysis.

\section{Results}

\subsection{Grain Morphology of the Deposited Layers}

Figure 2 shows the microstructure of the as-deposited samples under different powder feed rates. The typical microstructure of titanium alloys comprised of columnar $\beta$ grains that grow epitaxially from a substrate is obtained in sample A1 (Figure 2a). The columnar $\beta$ grains have a length in the order of millimeters and will further increase as more layers are deposited. It is noted that the grain boundaries in the last layer are not visible. As shown in Figure 2c,d, grain boundaries are clearly observed throughout the entire section. As expected, an increase in the powder feed rate substantially promotes the formation of equiaxed $\beta$ grains. However, it fails to prevent the formation of columnar $\beta$ grains in the overlap zones (indicated by the white box). As a result, a mixed equiaxed-columnar microstructure that is highly alternant is obtained. As indicated by the black arrows, some columnar $\beta$ grains that extended over several layers still exist outside the overlap zones in Figure $2 b, c$. The number of individual columnar $\beta$ grains decreased with the increasing powder feed rate, and almost no columnar $\beta$ grains exist outside the overlap zones in Figure 2d,e. Furthermore, the aspect ratio of the columnar $\beta$ grains in the overlap zone is significantly reduced, and a microstructure containing fully equiaxed $\beta$ grains is achieved when the powder feed rate reached $50 \mathrm{r} / \mathrm{min}$ (Figure 2e). However, the length-width ratio of the equiaxed grains in the overlap zone is slightly larger than that outside the overlap zone. 


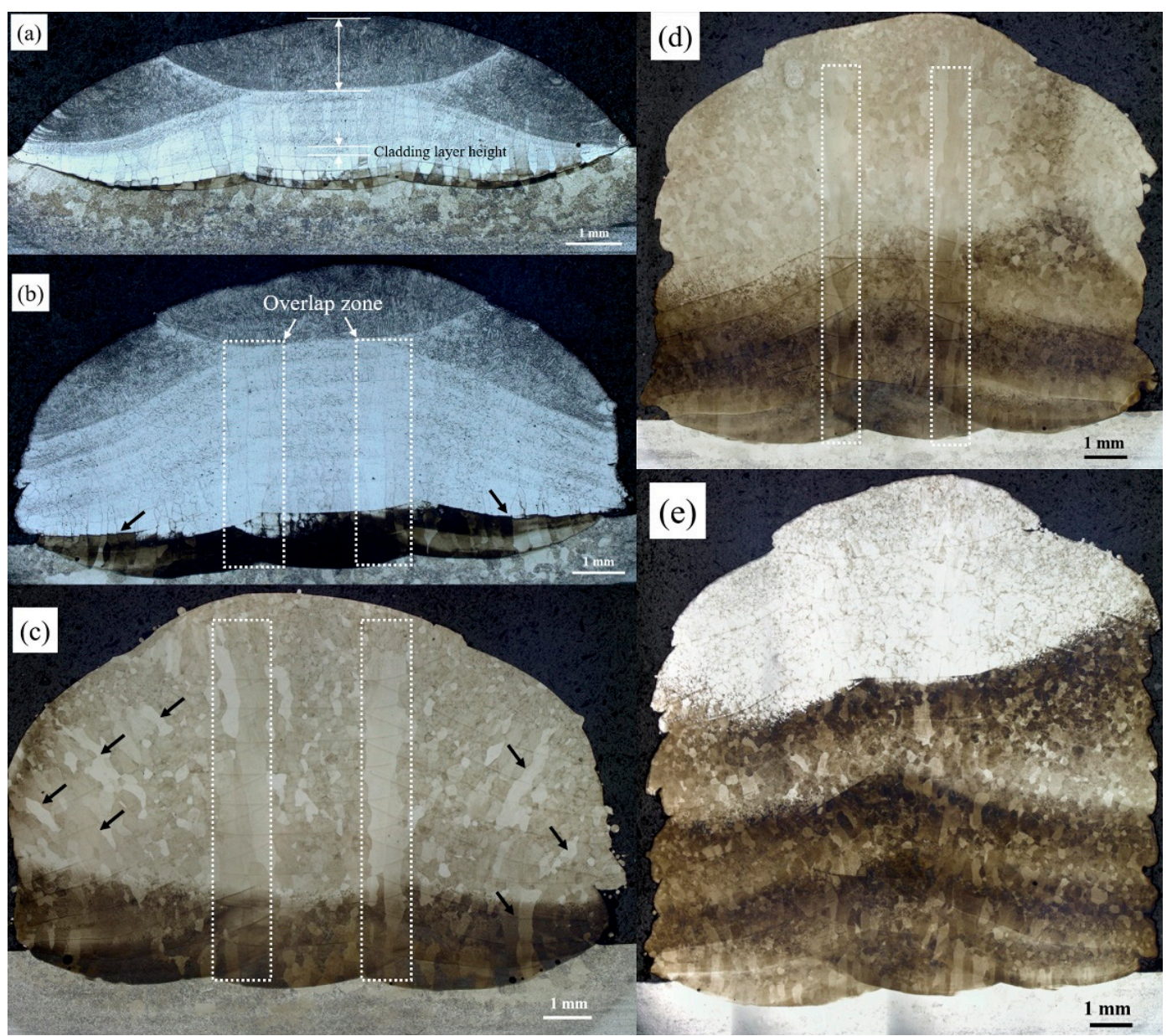

Figure 2. Grain morphology of the as-deposited samples, (a-e) sample A1 to A5 as the powder feed rate increases from 10 to $50 \mathrm{r} / \mathrm{min}$.

In addition, there is a pronounced contrast between the upper (bright region) and the lower parts (dark region) of the samples; moreover, the volume fraction of the dark region increased as more cladding layers were deposited. This coincides with the observations in the previous studies, and it usually be attributed to the unevenly precipitated $\alpha$ phase [21]. It should be noted that the last layer of samples A1 and A2 is darker than the middle layers. The nonuniform corrosion may be caused by cellular segregation, since more cellular structures were reserved in the last layer. The fusion lines clearly outlined the molten pool traces. The deposition height and the cladding layer height of the samples as a function of powder feed rate are displayed in Figure 3. The deposition height increased from $1250 \pm 60 \mu \mathrm{m}$ to $1620 \pm 108 \mu \mathrm{m}$ when the powder feed rate increased from $10 \mathrm{r} / \mathrm{min}$ to $30 \mathrm{r} / \mathrm{min}$, and it was almost kept constant when the powder feed rate further increased. Different from the deposition height, the cladding layer height increased linearly with an increase in the powder feed rate. This indicates that the remolten depth (the difference between the deposition height and cladding layer height) reduced with an increasing powder feed rate.

In the high magnification images, the solidification microstructure of the samples under different powder feed rates can be observed. The last cladding layer is composed of randomly orientated cellular structures and epitaxial cellular structures. As shown in Figure 4a, within each columnar $\beta$ grains, the epitaxial cellular arrays grow from the bottom into the center of the molten pool, and it extended over multiple layers until they are blocked by the randomly orientated cellular structure at the top of the last layer. In Figure $4 b$, the epitaxial cellular arrays extending over multiple layers only exit in the overlap zone. The volume fraction of the randomly orientated cellular structure in the last layer clearly increased in sample A2 compared to sample A1. Randomly orientated cellular structures dominate 
the regions outside the overlap zone. In Figure $4 c$, almost no epitaxial cellular array extends over multi-layers in the overlap zone, and the equiaxed $\beta$ grains dominated the whole sample.

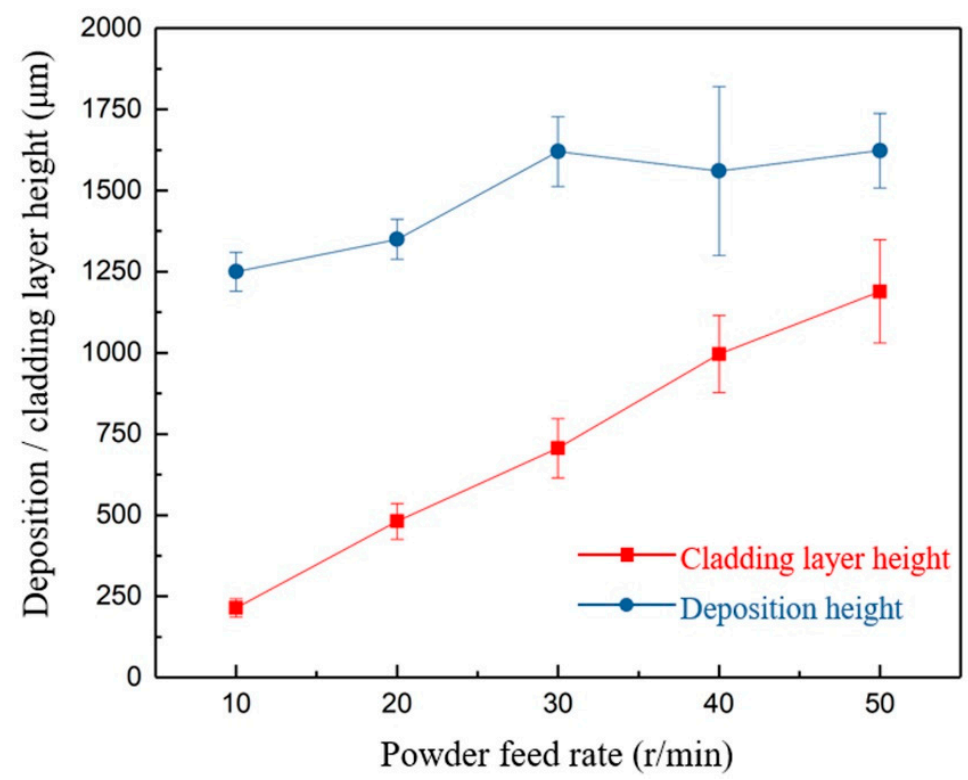

Figure 3. The deposition height and cladding layer height under different powder feed rates.
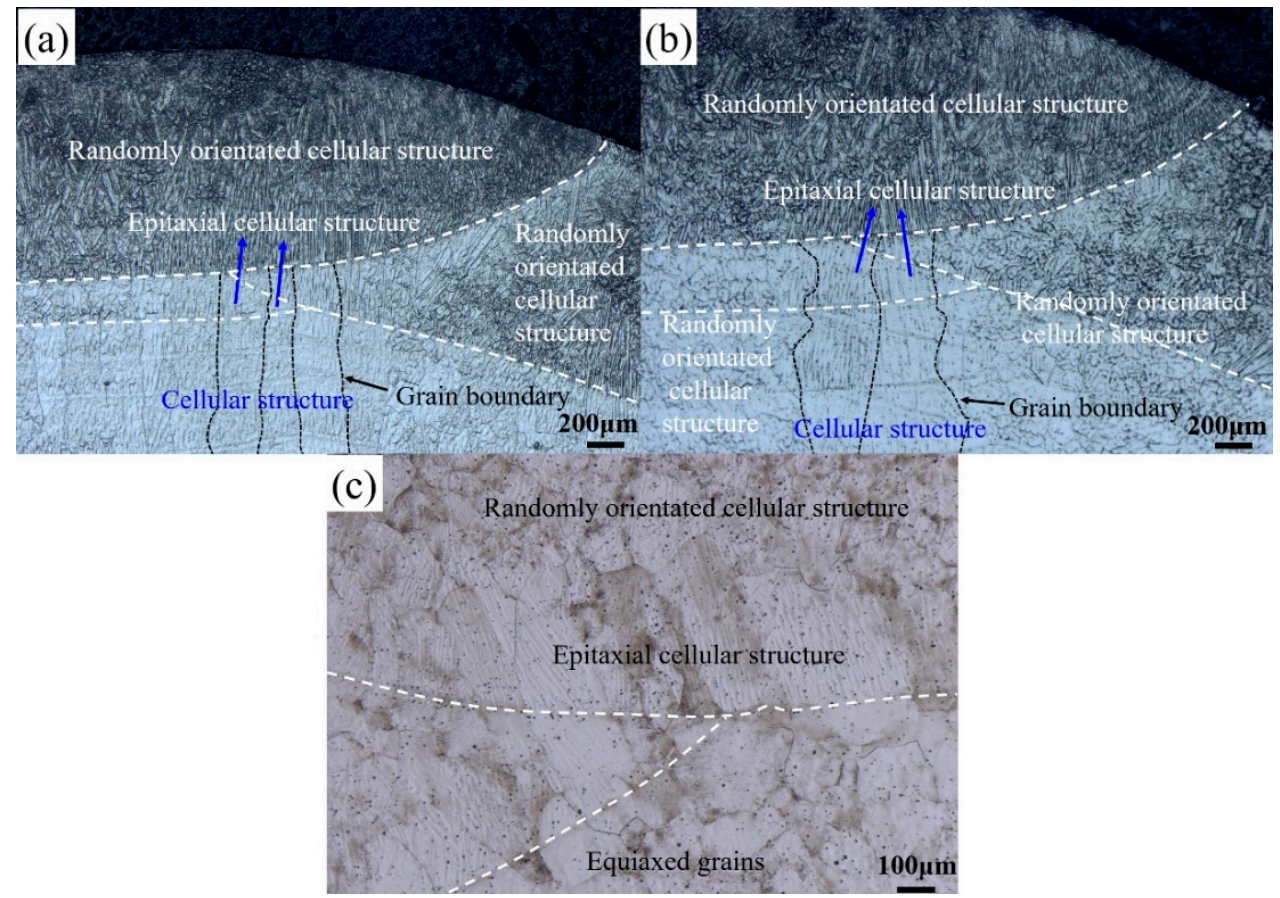

Figure 4. Solidification microstructure in the overlap zone of sample A1 (a), sample A2 (b), and sample A5 (c).

\subsection{Local Texture of the Deposited Layers}

EBSD was performed to investigate the influence of powder feed rate on the local texture in the overlap zones. Figure 5 shows the orientation map of $\alpha$ and $\beta$ phases and the corresponding pole figures in the overlap zone. Almost no $\alpha$ phase precipitated during the deposition and the subsequent cooling processes of sample A1 and A2. The volume fraction of $\beta$ phase in sample A1 and A2 reached $98.9 \%$ and $99.4 \%$, respectively. However, in sample A4, the volume fraction of the $\beta$ phase is about 
$74.7 \%$ and the distribution of the $\alpha$ phase is quite uneven (Figure $5 \mathrm{~g}$ ). It indicates that the deposited layers undergo the thermal cycles with different durations and amplitudes when different powder feed rates were adopted.

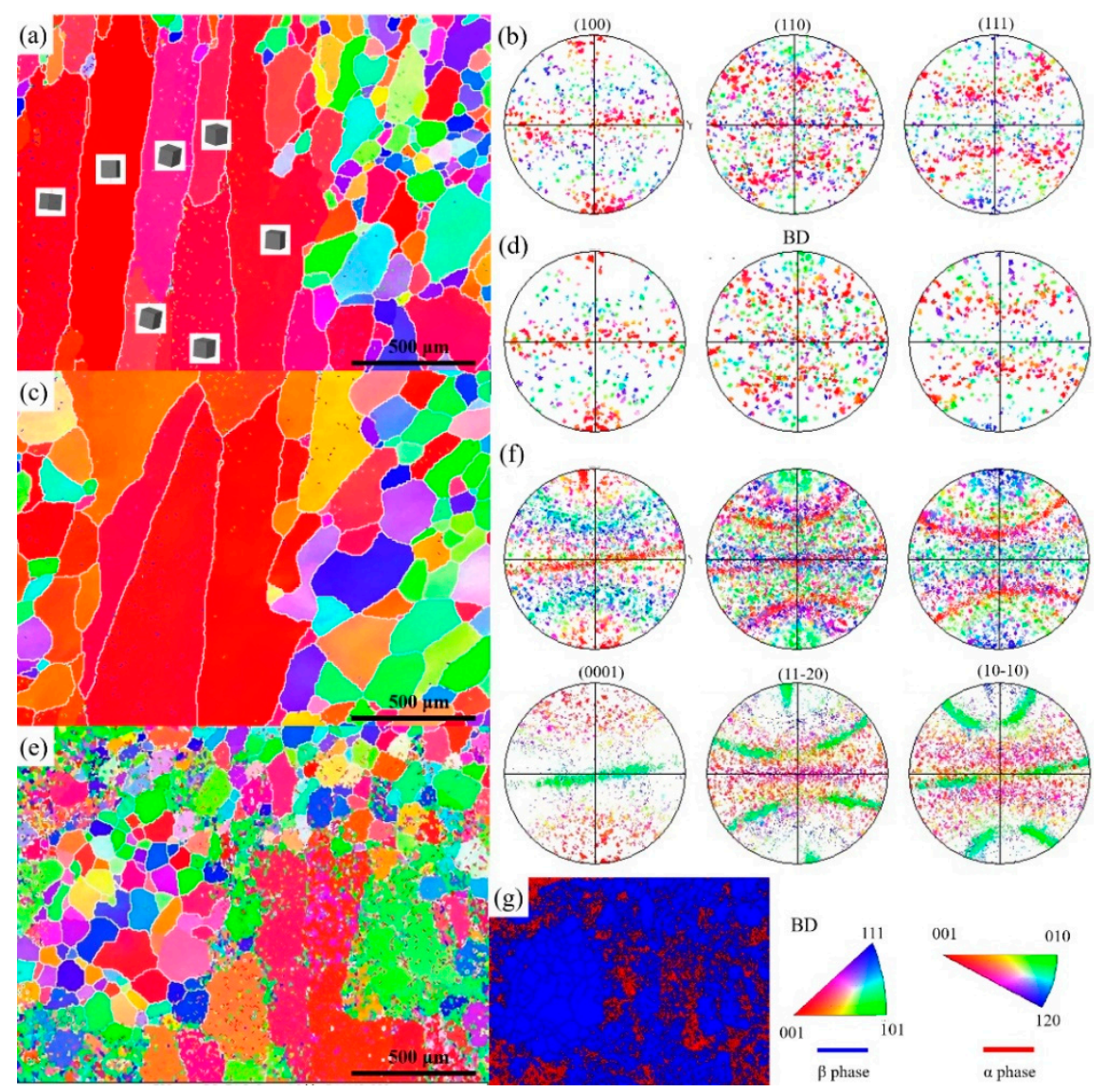

Figure 5. $(\mathbf{a}, \mathbf{b})$ Orientation map of the $\beta$ phase and the corresponding pole figures in the overlap zone of sample A1; (c,d) orientation map of the $\beta$ phase and the corresponding pole figures in the overlap zone of sample A2; $(\mathbf{e}-\mathbf{g})$ orientation map of the $\alpha$ and $\beta$ phases and the corresponding pole figures, and the phase distribution map in the overlap zone of sample A4.

As shown in Figure 5a, equiaxed $\beta$ grains are observed with the help of EBSD in the region of sample A1 where no grain boundary is visible under an optical microscope. The three-dimensional crystal orientation of the $\beta$ phase shows that the $<100>$ directions of the columnar $\beta$ grains are parallel to or nearly parallel to the build direction. The orientation map also suggests that there is no crystallographic misorientation across the adjacent cellular inside a single grain. The pole figures of the $\beta$ phase reveal a dominant $<100>$ fiber texture component in the columnar $\beta$ grains, whereas there is a random orientation distribution in the equiaxed $\beta$ grains (Figure $5 b$ ). The orientation map of the $\beta$ phase and the corresponding pole figures in the overlap zone of sample A2 are shown in Figure $5 c, d$. The orientation map confirmed the alternant equiaxed-columnar $\beta$ grain morphology. The pole figures of sample A2 are similar to those of sample A1. The orientation map of $\alpha$ and $\beta$ phases, and the corresponding pole figures in the overlap zone of sample A4 are shown in Figure 5e,f. It can be seen from the pole figures that the $\beta$ grains are more isotropic in a crystallographic texture. Furthermore, the (0001) and (11-20) pole figures of the $\alpha$ phase have a very similar appearance to the (110) and (111) pole figures of the $\beta$ phase, as the Burgers orientation relationship was obeyed during the $\beta \rightarrow \alpha$ phase transformation. 


\subsection{Thermal Conditions of the Molten Pool}

In this study, the scale of the deposited layers is big with a spot diameter of $5 \mathrm{~mm}$. In order to reduce the computational cost, a different set of processing parameters $(\mathrm{P}=1000 \mathrm{~W}, \mathrm{~V}=12 \mathrm{~mm} / \mathrm{s}$, $\mathrm{M}=0.5 \mathrm{~g} / \mathrm{s}$ ) with a spot diameter of $3 \mathrm{~mm}$ was used to calculate the thermal conditions of the molten pool. The powder feed rate approximately equals $30 \mathrm{r} / \mathrm{min}$. The calculated temperature and velocity profile are shown in Figure 6. Figure 6a shows that the temperatures within the molten pool vary significantly. Figure $6 \mathrm{~b}$ indicates an annular convection around the center of the molten pool, and the flow velocity of the liquid metal is about $0.08 \mathrm{~m} / \mathrm{s}$. The highest temperatures are located at the laser irradiation area. The maximum temperature within the molten pool is about $2707 \mathrm{~K}$, which is $779 \mathrm{~K}$ above its melting temperature of $1928 \mathrm{~K}$. In Wen and Shin's study, the maximum temperature within a molten pool of AISI 316 SS is around $2300 \mathrm{~K}$, which is about $40 \%$ above its melting temperature of $1673 \mathrm{~K}$ [22]. The thermal gradient across the molten pool is very large, ranging between $10^{5}$ and $10^{6} \mathrm{~K} / \mathrm{mm}$. The temperature and temperature gradient within the molten pool at different positions along the marker lines are presented in Figure 6c-e. As shown in Figure $6 c$, the temperature gradient decreased gradually from the bottom to the top of the molten pool along the solid-liquid interface. The temperature increased linearly from the bottom to the surface of the molten pool along Line 2, while the temperature gradient increased firstly and then decreased (Figure 6d). From the rear to the front of the molten pool, both the temperature and temperature gradient gradually increased and then decreased drastically (Figure 6e).
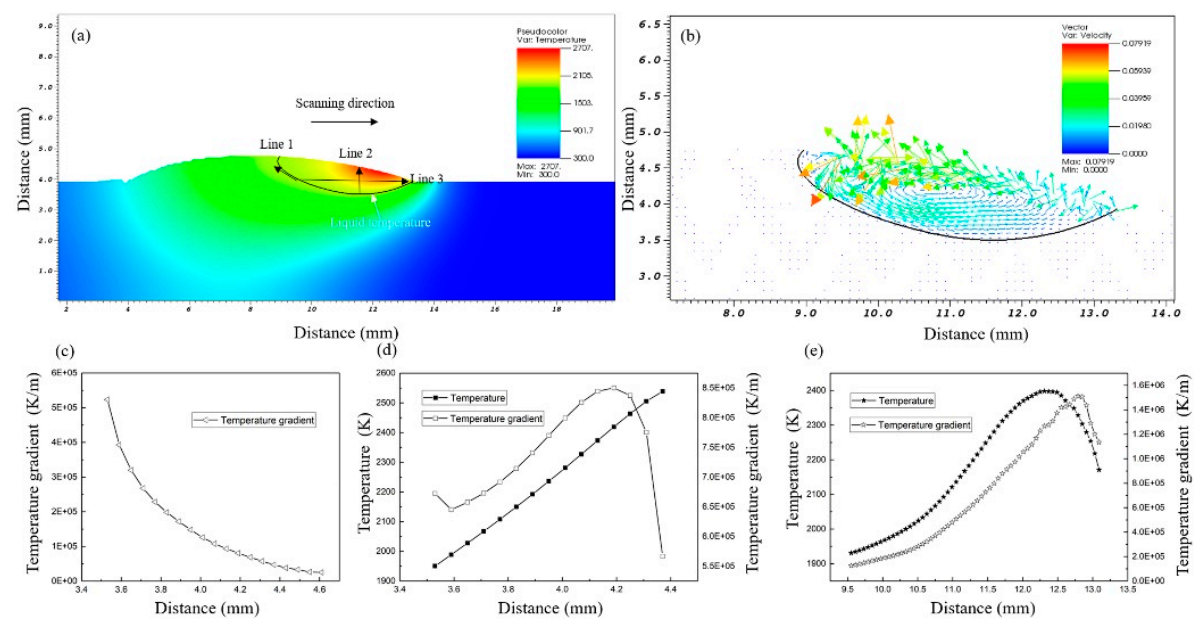

Figure 6. (a,b) The calculated temperature and velocity fields of the DED; (c-e) temperature and temperature gradient along lines 1,2 , and 3 .

\section{Discussion}

\subsection{Formation of Equiaxed $\beta$ Grains in the Deposited Layers}

Ti5Al2Sn2Zr4Mo4Cr is regarded to be easier to achieve equiaxed $\beta$ grains during AM compared to Ti6Al4V alloy, because the $\mathrm{Cr}$ and Mo elements could generate constitutional supercooling in front of the solid/liquid interface. Although solute segregation always unavoidably occurs during solidification, however, only specific solutes can refine grains remarkably while others may have a marginal effect [23]. The relative contribution of alloying elements to constitutional supercooling can be assessed using the growth restriction factor, $\mathrm{Q}$ [24]. A larger $\mathrm{Q}$ value means a quicker development of constitutional supercooling in front of the solid/liquid interface and benefits the nucleation on available substrate particles. According to Bermingham et al.'s study, in a Ti-X system, the $\mathrm{Q}$ values of $\mathrm{Cr}, \mathrm{Mo}, \mathrm{Al}$, and $\mathrm{V}$ are 6.5, 1.5, 0, and 0 [25,26]. However, research studies on DED Ti6A12Zr2Sn3Mo1.5Cr2Nb [8] and Ti6Al2Zr1Mo1V [27] titanium alloys showed that the columnar $\beta$ grains still dominate the microstructure over a wide processing window, since the addition of alloying 
elements in Ti5Al2Sn2Zr4Mo4Cr is not enough to trigger homogeneous nucleation in the constitutional supercooling zone.

The presence of heterogeneous nucleants in the supercooled zone also plays an important role in the formation of equiaxed $\beta$ grains during AM. In this study, the nucleant particles were introduced into the molten pool by increasing the powder feed rate. The partially melted powder particles are effective nucleant sites, since the metal melts can wet these particles completely, and the grains can grow without overcoming any nucleation barrier [16].

As shown in Figure 4, the last cladding layer is composed of an epitaxial cellular structure and randomly orientated cellular structure under different powder feed rates. It appears that the formation of an epitaxial cellular structure at the bottom of the molten pool during DED is unavoidable. A similar result was also reported in wire arc additive manufactured (WAAM) titanium alloys [17]. Conservative estimates of average bulk thermal gradients across the molten pool during WAAM is of the order of $10^{4} \mathrm{~K} / \mathrm{m}$, and it is thought to be too steep for the formation of equiaxed grains. According to the calculated results in Section 3.3, the thermal gradients of DED at the bottom of the molten pool were about 10 to 100 times larger than those of WAAM.

Another factor that may be related to the growth of an epitaxial cellular structure is that the captured powder particles are almost completely melted, as it takes a longer time for the powder particles to reach the bottom of the superheated molten pool. As mentioned, the formation of equiaxed grains is difficult without the presence of heterogeneous nucleation. With a low volume fraction of the equiaxed grains in front of the solid/liquid interface, a microstructure of fully columnar grains would be obtained [28]. As a result, the epitaxial cellular structure dominated the bottom part of the molten pool in DED titanium alloys.

As shown in Figure $6 \mathrm{c}$, the temperature gradient at the top of the molten pool is about $10^{4} \mathrm{~K} / \mathrm{m}$, so the solidification conditions are more favorable for the nucleation and growth of equiaxed dendrite. However, as mentioned above, it still seems too large to allow a constitutional supercooling zone to develop in front of the solid/liquid interface. Other factors that could reduce the temperature gradient, such as latent heat and melt turbulence, were also considered [17]. In addition, the temperature rise of the powder particles is very limited before being captured [29], so they could act as chilling sources. As a consequence, the temperature of the molten pool, as well as the temperature gradient, will reduce when more cold powder particles were captured. Furthermore, the experiment results showed that the powder injection could affect the molten pool superheat [29], and increasing the powder feed rate will decrease the molten pool temperature [30]. In the CFD model, the mass was added to the molten pool at the locations $40-80 \mu \mathrm{m}$ beneath the liquid/gas interface. Hence, the effect of cold powder particles on the temperature field of the molten pool could not be accurately estimated. Considering the energy conservation in a stable molten pool, a simplified model of temperature drop caused by the captured cold powder particles was given as

$$
\begin{gathered}
c_{l} m\left(T_{m p}-T\right)=m_{p}\left[c_{s}\left(T_{l}-T_{p}\right)+c_{l}\left(T-T_{l}\right)+h\right] \\
w=\frac{m_{p}}{m} .
\end{gathered}
$$

On the left hand side of Equation (9) is the heat loss of the molten pool, and on the right hand side is the heat transfer to the powder particles when more powder particles were injected into the stable molten pool. Where $c_{l}$ is the specific heat of the liquid metal, $c_{s}$ is the specific heat of the solid metal, $T_{m p}$ is the temperature of the molten pool, $T$ is the temperature of liquid metal after the powder particles melted, $T_{l}$ is the liquidus temperature, and $h$ is the latent heat of fusion. Substituting the material properties into Equation (9), the temperature drop is obtained,

$$
T_{m p}-T=T_{m p}-\frac{T_{m p}-134.8 w}{w+1} .
$$


Equation (11) suggests that the temperature drop is considerable, and the increase in powder particles amount equal to $1 \%$ of the mass of the molten pool will cause a temperature drop of $20-30 \mathrm{~K}$. A similar method has been used to analyze the effects of suspension casting on the solidification of GCr15 steel ingot [31]. Apply Equation (11) to the calculated temperature field, the effects of powder particles on the temperature field of the molten pool could be estimated. Figure 7 exhibits the effects of an increased powder feed rate on the superheat of the molten pool. It can be seen that an increase in powder particles amount equal to $1 \%$ of the mass of the molten pool would reduce the degree of superheat about $20 \mathrm{~K}$, and it even produced a supercooled zone at the tail of the molten pool (as indicated in Figure $7 \mathrm{~b}$ ). It means that with a larger powder feed rate, a thermal condition that is favorable for equiaxed grains to nucleation and growth was obtained at the rear of the molten pool.
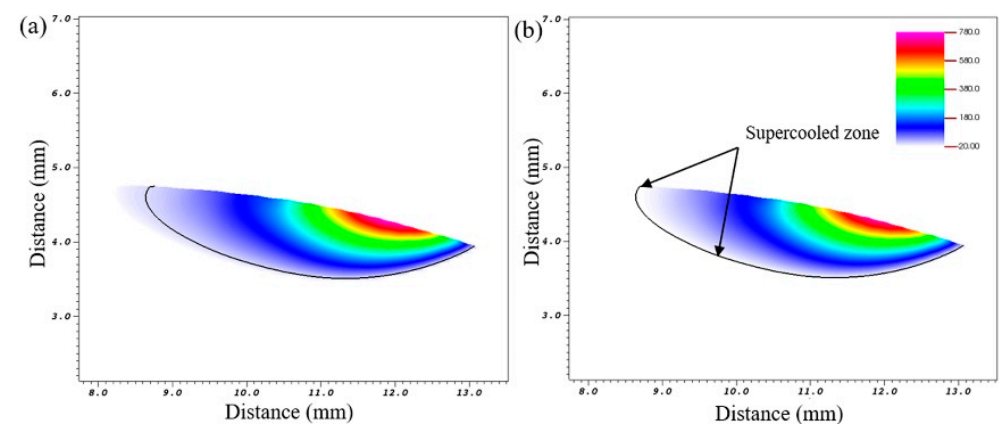

Figure 7. (a) The degree of overheat of the original molten pool; (b) the degree of overheat after an increase in powder particles amount equals $1 \%$ of the mass of the molten pool.

\subsection{Effect of Remelting on $\beta$ Grain Morphology Evolution}

The alloying elements with large $Q$ values, heterogeneous nucleants, and suitable thermal conditions in the molten pool are the key factors for the formation of equiaxed $\beta$ grains in a single cladding layer. However, as shown in Section 3.1, the formation of equiaxed $\beta$ grains in a single cladding layer could not guarantee the achievement of fully equiaxed microstructure in a block sample. Usually, the randomly orientated cellular structure will be completely remolten during the deposition of a new layer under a wide process window. Thus, typical full columnar $\beta$ grains will be obtained. The volume fraction of a randomly orientated cellular structure increased, and the remolten depth decreased when a higher powder feed rate was applied. The remaining randomly orientated cellular structure breaks off the continuity of the epitaxial growth of the cellular structure. However, the margin of the arc-shaped previous layer was almost totally remelted (Figure 8a). The epitaxial cellular structure grows naturally from the previous layer and leads to the formation of columnar grains when a new layer was deposited at the overlap zone (Figure 8b). As indicated by the ellipse in Figure $8 c$, increasing the volume fraction of the randomly orientated cellular structure reduced the width of the epitaxial growth zone. In this study, the widths of the columnar grains zone in samples A2, A3, and A4 are $1097 \pm 151 \mu \mathrm{m}, 1040 \pm 310 \mu \mathrm{m}$, and $907 \pm 101 \mu \mathrm{m}$, respectively. With the further increase in the powder feed rate, the continuity of the epitaxial growth of the cellular structure in the overlap zone is broken off, and a fully equiaxed microstructure was obtained. Generally, the preservation of equiaxed $\beta$ grains in the overlap zone during the depositing of a new cladding layer is critical for the grain morphology control. 
(a)

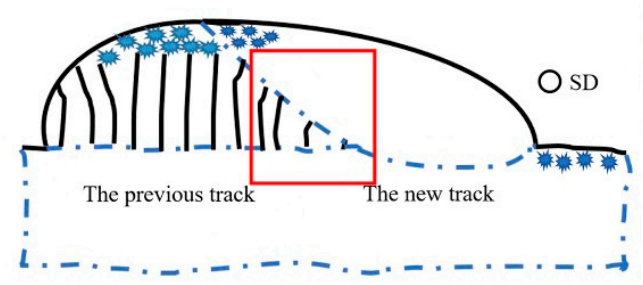

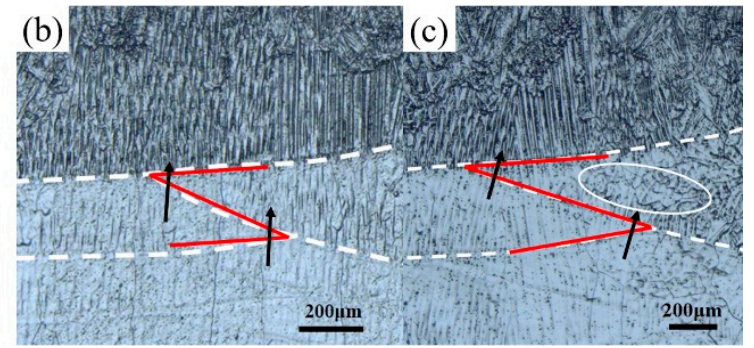

Figure 8. (a) The schematic of the remolten in the overlap zone; (b) the overlap zone of sample A1 (c) the overlap zone of sample A2. SD is the scanning direction.

\section{Conclusions}

In this work, the thermal conditions of the molten pool during DED were calculated. The effects of powder feed rate on $\beta$ grain morphology evolution were investigated. The primary conclusions are as follows.

Each cladding layer is composed of a randomly orientated cellular structure and an epitaxial cellular structure. The formation of an epitaxial cellular structure at the bottom of the molten pool during DED is almost unavoidable due to the high temperature gradient and less partially melted powder particles.

Increasing the powder feed rate promotes the formation of equiaxed $\beta$ grains in a single cladding layer. From a low to high powder feed rate, fully columnar, mixed equiaxed-columnar, and fully equiaxed $\beta$ grains can be obtained. The $<100>$ fiber texture component dominates the columnar $\beta$ grains, whereas a random orientation distribution dominates the equiaxed $\beta$ grains.

The grain morphology is significantly affected by the remolten process. A total remelting of the equiaxed grains ensures the continuity of the epitaxial growth of the cellular structure and leads to the formation of columnar $\beta$ grains. Increasing the powder feed rate reduced the remolten depth and broke the continuity of the epitaxial cellular structure.

The effects of captured cold powder particles on the temperature field of the molten pool were estimated. The thermal conditions of the molten pool are more favorable for the nucleation and growth of equiaxed dendrite due to the chilling effects of the cold powder particles.

Author Contributions: Methodology, Q.Z.; formal analysis, Q.Z., S.Z., M.Z., J.C., and S.S.; investigation, Y.O., X.W., W.L.; writing — original draft preparation, Q.Z.; writing—review and editing, Q.Z., J.C., and X.W. All authors have read and agreed to the published version of the manuscript.

Funding: This research was funded by the National Key Technologies R\&D Program, Grant No. 2016YFB11000100, National Natural Science Foundation of China, Grant No. 51901085, the fund of the State Key Laboratory of Solidification Processing in NWPU, Grant No. SKLSP201807, and the Fundamental Research Funds for the Central Universities, Grant No. 21618325.

Conflicts of Interest: The authors declared that we have no conflicts of interest to this work.

\section{References}

1. Debroy, T.; Wei, H.; Zuback, J.; Mukherjee, T.; Elmer, J.; Milewski, J.; Beese, A.M.; Wilson-Heid, A.; De, A.; Zhang, W. Additive manufacturing of metallic components-Process, structure and properties. Prog. Mater. Sci. 2018, 92, 112-224. [CrossRef]

2. Huang, W.; Lin, X. Research Progress in Laser Solid Forming of High-Performance Metallic Components at the State Key Laboratory of Solidification Processing of China. 3D Print. Addit. Manuf. 2014, 1, 156-165. [CrossRef]

3. Neikter, M.; Åkerfeldt, P.; Pederson, R.; Antti, M.-L.; Sandell, V.H. Microstructural characterization and comparison of Ti-6Al-4V manufactured with different additive manufacturing processes. Mater. Charact. 2018, 143, 68-75. [CrossRef] 
4. Banerjee, D.; Williams, J. Perspectives on Titanium Science and Technology. Acta Mater. 2013, 61, 844-879. [CrossRef]

5. Tan, H.; Guo, M.; Clare, A.T.; Lin, X.; Chen, J.; Huang, W. Microstructure and properties of Ti-6Al-4V fabricated by low-power pulsed laser directed energy deposition. J. Mater. Sci. Technol. 2019, 35, 2027-2037. [CrossRef]

6. Zhai, Y.; Lados, D.A.; Brown, E.J.; Vigilante, G.N. Understanding the microstructure and mechanical properties of Ti-6Al-4V and Inconel 718 alloys manufactured by Laser Engineered Net Shaping. Addit. Manuf. 2019, 27, 334-344. [CrossRef]

7. Li, G.-C.; Li, J.; Tian, X.-J.; Cheng, X.; He, B.; Wang, H.-M. Microstructure and properties of a novel titanium alloy Ti-6Al-2V-1.5Mo-0.5Zr-0.3Si manufactured by laser additive manufacturing. Mater. Sci. Eng. A 2017, 684, 233-238. [CrossRef]

8. Zhang, Q.; Chen, J.; Guo, P.; Tan, H.; Lin, X.; Huang, W. Texture and microstructure characterization in laser additive manufactured Ti-6Al-2Zr-2Sn-3Mo-1.5Cr-2Nb titanium alloy. Mater. Des. 2015, 88, 550-557. [CrossRef]

9. Zhang, Q.; Chen, J.; Zhao, Z.; Tan, H.; Lin, X.; Huang, W. Microstructure and anisotropic tensile behavior of laser additive manufactured TC21 titanium alloy. Mater. Sci. Eng. A 2016, 673, 204-212. [CrossRef]

10. Carroll, B.E.; Palmer, T.A.; Beese, A.M. Anisotropic tensile behavior of Ti-6Al-4V components fabricated with directed energy deposition additive manufacturing. Acta Mater. 2015, 87, 309-320. [CrossRef]

11. Zhang, Q.; Chen, J.; Qi, Z.; Lin, X.; Tan, H.; Huang, W. A Processing Route for Achieving Isotropic Tensile Properties in Laser Solid Formed $\alpha+\beta$ Titanium Alloy. Met. Mater. Trans. A 2018, 49, 3651-3662. [CrossRef]

12. Kurz, W.; Fisher, D. Fundamentals of Solidification; Trans Tech Publications, Ltd.: Stafa-Zurich, Switzerland, 1998.

13. Vrancken, B.; Thijs, L.; Kruth, J.-P.; Van Humbeeck, J. Heat treatment of Ti6Al4V produced by Selective Laser Melting: Microstructure and mechanical properties. J. Alloy. Compd. 2012, 541, 177-185. [CrossRef]

14. Xue, A.; Lin, X.; Wang, L.-L.; Wang, J.; Huang, W. Influence of trace boron addition on microstructure, tensile properties and their anisotropy of Ti6Al4V fabricated by laser directed energy deposition. Mater. Des. 2019, 181, 107943. [CrossRef]

15. Wang, T.; Zhu, Y.; Zhang, S.; Tang, H.; Wang, H. Grain morphology evolution behavior of titanium alloy components during laser melting deposition additive manufacturing. J. Alloy. Compd. 2015, 632, 505-513. [CrossRef]

16. Zhang, Q.; Chen, J.; Wang, L.; Tan, H.; Lin, X.; Huang, W. Solidification Microstructure of Laser Additive Manufactured Ti6Al2Zr2Sn3Mo1.5Cr2Nb Titanium Alloy. J. Mater. Sci. Technol. 2016, 32, 381-386. [CrossRef]

17. Bermingham, M.; StJohn, D.; Krynen, J.; Tedman-Jones, S.; Dargusch, M. Promoting the columnar to equiaxed transition and grain refinement of titanium alloys during additive manufacturing. Acta Mater. 2019, 168, 261-274. [CrossRef]

18. Zhang, Q.; Chen, J.; Lin, X.; Tan, H.; Huang, W. Grain morphology control and texture characterization of laser solid formed Ti6Al2Sn2Zr3Mo1.5Cr2Nb titanium alloy. J. Mater. Process. Technol. 2016, 238, $202-211$. [CrossRef]

19. Zhu, Y.; Liu, N.; Tian, X.; Tang, H.; Wang, H. Characterization of microstructure and mechanical properties of laser melting deposited Ti-6.5Al-3.5Mo-1.5Zr-0.3Si titanium alloy. Mater. Des. 2014, 56, 445-453. [CrossRef]

20. Childs, H.; Brugger, E.; Whitlock, B.; Meredith, J.; Ahern, S.; Pugmire, D.; Biagas, K.; Miller, M.; Harrison, C.; Weber, G.H. VisIt: An End-User Tool For Visualizing and Analyzing Very Large Data. High Performance Visualization-Enabling Extreme-Scale Scientific Insight, Insight. 2012, pp. 357-372. Available online: https://escholarship.org/uc/item/69r5m58v (accessed on 1 December 2019).

21. Qiu, C.; Ravi, G.; Attallah, M. Microstructural control during direct laser deposition of a $\beta$-titanium alloy. Mater. Des. 2015, 81, 21-30. [CrossRef]

22. Wen, S.; Shin, Y. Modeling of transport phenomena during the coaxial laser direct deposition process. J. Appl. Phys. 2010, 108, 44908. [CrossRef]

23. Easton, M.; StJohn, D. Grain refinement of aluminum alloys: Part I. the nucleant and solute paradigms-A review of the literature. Met. Mater. Trans. A 1999, 30, 1613-1623. [CrossRef]

24. Bermingham, M.; Kent, D.; Zhan, H.; StJohn, D.; Dargusch, M. Controlling the microstructure and properties of wire arc additive manufactured Ti-6Al-4V with trace boron additions. Acta Mater. 2015, 91, 289-303. [CrossRef] 
25. Bermingham, M.; McDonald, S.A.; Dargusch, M.; StJohn, D. Grain-refinement mechanisms in titanium alloys. J. Mater. Res. 2008, 23, 97-104. [CrossRef]

26. Bermingham, M.; McDonald, S.A.; StJohn, D.; Dargusch, M. Beryllium as a grain refiner in titanium alloys. J. Alloy. Compd. 2009, 481, L20-L23. [CrossRef]

27. Li, J.; Wang, H. Aging response of laser melting deposited Ti-6Al-2Zr-1Mo-1V alloy. Mater. Sci. Eng. A 2013, 560, 193-199. [CrossRef]

28. Hunt, J. Steady state columnar and equiaxed growth of dendrites and eutectic. Mater. Sci. Eng. 1984, 65, 75-83. [CrossRef]

29. Frenk, A.; Vandyoussefi, M.; Wagnière, J.-D.; Kurz, W.; Zryd, A. Analysis of the laser-cladding process for stellite on steel. Met. Mater. Trans. A 1997, 28, 501-508. [CrossRef]

30. Hua, T.; Jing, C.; Xin, L.; Fengying, Z.; Huang, W. Research on molten pool temperature in the process of laser rapid forming. J. Mater. Process. Technol. 2008, 198, 454-462. [CrossRef]

31. Yu, Y.; Zhai, Q.J.; Xing, C.H.; Chen, J.B.; Hu, H.Q. Effects of suspension casting on solidification process of GCr15 steel ingot. J. Univ. Sci. Technol. B 1998, 20, 262-306.

(C) 2020 by the authors. Licensee MDPI, Basel, Switzerland. This article is an open access article distributed under the terms and conditions of the Creative Commons Attribution (CC BY) license (http://creativecommons.org/licenses/by/4.0/). 